\title{
Sectional integration of spatial impacts of environmental risks
}

\author{
J. Betáková ${ }^{1}$, M. Lorko ${ }^{1} \&$ J. Dvorský ${ }^{2}$ \\ ${ }^{1}$ Dubnica Institute of Technology, Slovakia \\ ${ }^{2}$ University of Žilina, Slovakia
}

\begin{abstract}
An effort to increase competitiveness of an area creates the platform for applying environmental management. It is a market oriented development process covering various sectional interests with the aim of making an integrated concept for further development. The aim of this study is to evaluate potential risks of effectiveness of spatial impact of selected tools of environmental management on regional development and the creation of references to make this activity more effective. The research method comes from the principle of multilevel complex analysis of particular factors influencing the development of residential settlement. As the practice is not a practice of isolated or comparative management, but of the infiltration through various subsystems levels, based on their efficiency, we concluded that their functionality is insufficient.

Keywords: environmental management, environmental risk, settlement system.
\end{abstract}

\section{Introduction}

Recently, the answers to current questions regarding safety, which are considered an inseparable part of life and space quality in which particular activities occur in objective time, have obtained the value of notice. A definition of environmental safety is presented in the terminology of safety management (2004). The terminological dictionary of terms in the area of crisis management and state defense planning administered by the Ministry of the Interior of the Czech Republic defines it in extended version as "the state when human society and ecological system interact with each other in a permanently sustainable way, all natural sources are fully available to individuals and there are mechanisms for the management of crisis and conflicts directly or indirectly connected with the 
environment. In this state threats associated with the environment and caused by nature or by society developed processes (eventually by their combination) either intentionally, unintentionally or caused by an accident are minimized. These threats can cause or make already existing social tension or armed conflict even worse. The vast majority of them do not respect the state borders and can often act globally" (2004). If we talk about sustainable development, we think of ecological security in environmental and social context, then, as Jelšovská and Mikulová [1] warn, contemporary deterioration of the environment is a greater threat for the planet's inhabitants than a well-equipped army.

\section{Environmental management as a tool of the sustainable spatial development policy}

The notion of environmental management is a general term; it can be set more politically, but also more administratively, organizationally or managerially. According to its orientation, there is preference for individual tools that are characterized by strong mutual cohesion. Basically, we can divide them into legislative, economic, organizational, regulative, planning and communicative, oriented to the information gathering. While these are more or less formal instruments, methods create the way of their usage. The main aim of environmental management is the protection and improvement of the environment by restraining negative environmental impacts, implementing the measures for the protection of the environment, influencing particular documentation (e.g. master plans) and legislation, and raising environmental awareness. Orientation to long-term goals, continuity and the permanence of these processes, the bonds between planning and implementation, and control of these processes are of great importance. The execution of all mentioned processes in the environment of partnership, participation, subsidiarity and coordination of the interests of all actors of this process is necessary.

\section{Master planning as a coordinating and spatially integrating tool of environmental management}

Master planning solves systematically and comprehensively spatial organization and the functional use of a territory, determines its principles, suggests objective and time coordination of the activities influencing the environment, ecological stability, cultural-historical values of the territory, spatial development and landscaping in accordance with the principles of sustainable development. The majority of the component laws in the field of environmental legislation matches the protection of the environment component in accordance with a master plan, or the permitting of specific activity or object in the process of land use planning or building permit. In this context, the master planning act makes the platform for the integration of the processes of the creation and protection of the environment and spatial-developmental processes. Individual activities, of manufacturing and non-manufacturing character, are presented and intersected in 
various ways in the area where it is possible to follow their cumulative and synergic influences and impacts. We are not able to affect their impact by simple data summarization gained in the process of environmental impact assessment of specific projects because it's possible to map cumulative and synergic influences and impacts in the best way in their spatial projection reflected by a master plan. We can say that master plans make the presumptions for permanent coincidence of all activities within the territory, the maximization of the use of its potential for development with a unique respect to the environment protection, acquiring ecological balance and securing sustainable development for the economical use of natural sources and for preserving natural, civilizational and cultural values.

Currently, in practice, there is a real fear of preferring commercial and political interests to an effective sustainable territorial development policy. In this context, the implementation of environmental management tools and methods gets the value of being noticed. We can say that it is a market-oriented development process covering various sectional interests and strategies with the aim of creating an integrated concept of the profiting development of a particular territory. It's unreal to expect the improvement of a spatial development situation and the activities connected with it without any systematic and synergic solution of particular problems. From a spatial development point of view, the inner quality of the institutions of public administration has an important influence on sustainable development. We need to be aware of the fact that municipalities and cities face the difficult conditions associated with the decay of a financial cohesion to regular financial flow. The position of the creator of the stimulations, the conditions for acquiring new investment source that is necessary for further development becomes dominant from the position of the regulations and the limits for private sector.

In reaching this goal, diagnostics of potential risks and a succession of the complex solution plan within the context of sustainable development of objective territorial unit is very important.

\section{Theoretical scopes of risk assessment}

As Šimák [2] states, risk management is an instrument for the identification of risk that can decrease the level of complex security; it's even the instrument for a risk analysis, its assessment, classification, setting the priorities and consequently even the instrument for its decrease. Thus, it becomes an inseparable part of the process of increasing the security and its consequences. It enables us to assess the weaknesses and strengths of management activities and creative processes, to improve technological and working processes and to improve the function of mentioned systems. Risk assessment is the process of determination of its intensity through the consideration of the possible extent of damage and losses that can cause a risk phenomenon as a risk consequence. Each manager should be aware not only of the risk and the reason for its origin, but even the characteristics of a negative event associated with its growth to a crisis. That is the result of its specific assessment (for more see [2]). The risk, from its structure point of view, can be defined even as a combination of the probability of the 
origin of a specific event and its consequences. Janošiková and Hudecová [3] state that each type of risk has its characteristic sources and factors that are classified to outer risk sources (external factors), e.g. economic, sociological, physical, technological, political, legal and inner risk sources (internal factors e.g. informative systems, management style, colleagues, organizational structure, employees' competences etc.). According to the Guidance of the Ministry of Finance of the Slovak Republic to risk management and analysis, we consider environmental risk as the risk being associated with a possible negative influence on the environment. Based on the methodology of the assessment of selected risks at a domestic level, the analysis of specific models HRVA (Hazard Risk Vulnerability Assessment) precedes the creation of the assessment model of natural risks in a specific area. The methodology of the assessment of natural risks was proposed by a synthesis of information of used HRVA models for the assessment of the risks and the environment vulnerability at domestic level applicable within the conditions of the Slovak Republic. Proposed progress of risk assessment consists of 9 partial steps - analysis of an area, risk identification, analysis of historical data on risks, the determination of the probability of the risk occurrence in the area, analysis of the area's vulnerability, the determination of a degree of area damage, setting the relevant risk score, assessment of a risk matrix and a risk comparison and the determination of the priorities of their decrease (for more also see [4] and [5]).

\section{Theoretical-methodological scopes}

In this study we analyzed the implementation of spatial impacts of economic instruments of the environment management on the development territory of a municipality. The assessment range is determined upon qualitative and quantitative assessment of the influence of emerging potential risks and barriers of the implementation of selected instruments for the execution of the conceptual aims of the development of objective spatial structure related to a criteria of sustainable development, based on the compatibility of conceptual sectorial aims with the priorities of territorial development of specific territory with conceptual and strategic developmental materials of an objective spatial unit. The assessment is bound to selected economic instruments of environmental management having the assumption of significant impacts on the environment in this field: housing, manufacture, civic amenities and social infrastructure, sport and recreation, traffic, technical infrastructure, sewage, landscaping, natural elements and components (also see [6] and [7]). The assessment of instruments consists of the main formal-methodological steps:

1. The review of individual instruments of their assessment by a 5 grade scale concerning the acquired criteria of sustainable development (significant influence, positive influence, slightly positive influence, negative influence, indetermination of the influence)

2. The formulation of the compatibility between particular conceptual aims with the assessment of a 4 grade scale (compatibility, partial compatibility, incompatibility, indetermination) 
3. The assessment of conceptual aims in terms of their negative or positive impacts concerning

- wider relations (international agreements, sectional conceptions, plans and programmers, trans boundary impacts, master plans, activities and conceptions already assessed according to the act on environment impact assessment);

- population impacts (health implications, comfort factor, socioeconomic impacts);

- impacts on the natural environment (air, climate, water, soil, mineral environment, flora and fauna, protected elements of nature conservation, ecosystems);

- impacts on the urbanized environment (cultural heritage, housing, social infrastructure, recreation, spas, traffic, technical infrastructure, manufacture, waste management);

- $\quad$ specific impacts.

The overall assessment of significant expected impacts on the environment, the definition of cumulative impacts and the scheme of measures for the mitigation of impacts.

\section{Work methodology}

The study focuses on the spatial implementation of economic instruments of environmental management and the assessment of potential risks. We analyzed a master plan of direct and indirect economic environmental instruments in the context of their local projection and sustainable development of the objective territory. Fees, payments, revenues, taxes, recoveries, fines, penalties, grants, donations, subventions, loans, tolls, backup systems, insurances and bonds were analyzed here. We generated economic instruments of environmental management by sectorial implementation into the groups for economic instruments applied in these fields:

1. Water management (WatM);

2. Waste management (WasM);

3. Air protection (AP);

4. Forest management (FM);

5. Agriculture land (AL);

6. Environmental aspects of the environment protection in the tax system of the Slovak Republic (EP).

Specific instruments and their spatial impacts are examined in the relation to legislative-legal regulations in the Slovak Republic, aiming to integrate them into the preparation process of the municipality master plans and the system of strategic planning. Progressiveness of the approach consists of the analysis and selection of suitable planning and information mechanisms with the purpose of expanding the methodological basis for mutual interaction of particular types of planning at a local level and of spatial impacts of selected activities 
participating in the management of the development potential of the settlement structure and following implemental and methodological recommendations.

The study issues from the presumption that the integrating factor for effective spatial development compatible with the goals of sustainable development is spatial quality and its relative time-spatial continuity of the planning at a national, regional and local level. The principle of sustainability makes the presumption and a basic statement for the assessment of developmental potential of the territory in the context of generating the origin of potential risks with the goal of preceding the negative impact on settlement development preventively.

There are methods of logic research, comparative method and analyticsystematic method in the search for specific instruments of environment management, the method of induction and deduction in conclusions practically applied in this work (also see [8] and [9]). Complex analysis based on the theory of systematic analysis and the synthesis of theoretical and empirical progress in the research can be considered as a basic method of the research. Determining factors of contemporary development of urban structures with the use of the methods of complex spatial assessment, comparison, economic analyses and statistical methods are researched by systematic approach. The process itself can be divided into 3 developmental stages:

- Analysis of theoretical information and practical experiences compatible with the implementation of particular instruments of the environment management and its spatial impacts on the development of the settlement unit;

- Analysis, quantification and the use of qualitative methods in the assessment of synergic and cumulative impacts in the context of sustainable development of the settlement and the system of planning mechanisms;

- Summary and formulation of the conclusions for practical application of progressive approaches towards the assessment of developmental spatial potential of the settlement unit.

\section{Methodology of variance analysis of selected risks}

The objective case study (selected file - 180 respondents) dealt with the perception of dominant environmental risks and their impacts. It's possible to determine the identity or the diversity of average values of selected risk between particular fields with the help of a quantitative method of the analysis of selected risks' variance in selected fields. Specific scales have been rated from 1 to 10 . Variance analysis of selected risks plays a significant role in assessing the survey and discussion in a particular field. Variance analysis of selected risks consists of the following stages:

- Define selected characteristics (average, variance) from the objective case study in selected fields and risks.

- Make a decision on the suitability of the use of parametric or nonparametric test variance analysis of the risks regarding the conditions set on their realization. 
- Determine if average values of selected risks between the fields are identical by testing the variance the assumptions of selected risks using the parametric F-test and non-parametric Kruskal-Wallis test.

\section{Variance analysis of selected risks}

The process of the selected file was carried out with the support of statistical software STATGRAPHICS CENTURION XV [10]. Elementary selective characteristics, such as average value and the variance, are calculated in tables stated below.

Table 1: Average values of selected risk according to fields (source: own data processing).

\begin{tabular}{|c|c|c|c|c|c|c|}
\hline \multirow[b]{2}{*}{ Risks } & \multicolumn{6}{|c|}{ Fields } \\
\hline & $\begin{array}{c}1 . \\
\text { WatM }\end{array}$ & $\begin{array}{c}2 . \\
\text { WasM }\end{array}$ & $\begin{array}{l}3 . \\
A P\end{array}$ & $\begin{array}{c}4 . \\
F M\end{array}$ & $\begin{array}{c}5 . \\
A L\end{array}$ & $\begin{array}{c}6 . \\
E P\end{array}$ \\
\hline Financial risk & 1.32 & 3.84 & 2.06 & 2.79 & 3.74 & 4.15 \\
\hline Operational risk & 2.28 & 1.71 & 3.04 & 3.98 & 6.97 & 1.14 \\
\hline Personal risk & 5.87 & 6.14 & 6.67 & 6.81 & 2.57 & 1.96 \\
\hline Legislative risk & 5.18 & 5.9 & 5.78 & 5.71 & 6.05 & 4.51 \\
\hline Security risk & 6.40 & 6.84 & 6.98 & 7.07 & 6.04 & 5.93 \\
\hline Weak law enforcement & 6.48 & 7.18 & 1.89 & 2.68 & 4.81 & 3.35 \\
\hline $\begin{array}{l}\text { Territory } \\
\text { competitiveness }\end{array}$ & 4.15 & 2.73 & 6.41 & 4.15 & 5.15 & 6.47 \\
\hline
\end{tabular}

Table 2: Variance values of selected risk according to fields (source: own data processing).

\begin{tabular}{|l|c|c|c|c|c|c|}
\hline \multirow{2}{*}{\multicolumn{1}{|c|}{ Risks }} & \multicolumn{6}{c|}{ Fields } \\
\cline { 2 - 7 } & $\begin{array}{c}\mathbf{1 .} \\
\text { WatM }\end{array}$ & $\begin{array}{c}\mathbf{2 .} \\
\text { Was M }\end{array}$ & $\begin{array}{c}\text { 3. } \\
\boldsymbol{A P}\end{array}$ & $\begin{array}{c}\text { 4. } \\
\boldsymbol{F M}\end{array}$ & $\begin{array}{c}\mathbf{5 .} \\
\boldsymbol{A L}\end{array}$ & $\begin{array}{c}\mathbf{6 .} \\
\boldsymbol{E P}\end{array}$ \\
\hline Financial risk & 0.15 & 0.24 & 0.12 & 0.85 & 1.13 & 1.02 \\
\hline Operational risk & 0.78 & 0.85 & 0.64 & 0.23 & 1.81 & 1.64 \\
\hline Personal risk & 1.84 & 1.21 & 1.06 & 2.21 & 3.14 & 0.81 \\
\hline Legislative risk & 0.85 & 0.64 & 0.71 & 0.91 & 0.81 & 1.03 \\
\hline Security risk & 1.36 & 1.42 & 1.51 & 1.79 & 1.84 & 1.74 \\
\hline Weak law enforcement & 1.05 & 2.68 & 0.94 & 2.14 & 1.19 & 1.64 \\
\hline $\begin{array}{l}\text { Territory } \\
\text { competitiveness }\end{array}$ & 1.25 & 1.36 & 2.41 & 0.75 & 1.74 & 2.00 \\
\hline
\end{tabular}


Analysis of variance is carried out using a parametric F-test, respectively, and the non-parametric Kruskal-Wallis test. A parametric test can be performed subject to the following two conditions:

- Homoscedasticity - risks variance identity between particular fields. Results are summarized in Tab. 3.

- Values normality - probable model of normal diversion of risk assessment in particular fields. Results are summarized in Tab. 4.

A non-parametric Kruskal-Wallis test can be performed subject to the presence of variance homoscedasticity. However, risk values in particular fields are not distributed normally.

Table 3: Bartlett's test for homoscedasticity verification (source: own data processing).

\begin{tabular}{|l|c|}
\hline \multicolumn{1}{|c|}{ Risks } & $\begin{array}{c}\text { Bartlett's test } \\
{[\text { P-value }]}\end{array}$ \\
\hline Financial risk & 0.154 \\
\hline Operational risk & 0.078 \\
\hline Personal risk & 0.104 \\
\hline Legislative risk & 0.687 \\
\hline Security risk & 0.254 \\
\hline Weak law enforcement & 0.085 \\
\hline Territory competitiveness & 0.028 \\
\hline
\end{tabular}

Table 4: Pearson's $\mathrm{x}^{2}$-test for risk value normality verification (source: own data processing).

\begin{tabular}{|l|c|}
\hline \multicolumn{1}{|c|}{ Risks } & $\begin{array}{c}\text { Pearson's } \mathbf{x}^{2} \text {-test } \\
{[\text { P-value] }}\end{array}$ \\
\hline Financial risk & 0.075 \\
\hline Operational risk & 0.047 \\
\hline Personal risk & 0.002 \\
\hline Legislative risk & 0.359 \\
\hline Security risk & 0.124 \\
\hline Weak law enforcement & 0.311 \\
\hline Territory competitiveness & 0.037 \\
\hline
\end{tabular}


Bartlett's test results in 95 per cent probability of accepting the assumptions of identical variance of financial risk, legislative risk and security risk among fields. Heteroscedasticity - variance heterogeneousness consists of 95 per cent probability of operational risk, personal risk, weak law enforcement and territory competitiveness in particular fields. Pearson's $\mathrm{x}^{2}$-test results in 5 per cent importance of financial risk, legislative risk and security risk having regular distribution in selected fields. Operational risk, personal risk, territory competitiveness risk and weak law enforcement risk don't consist of regular distribution in particular fields of case study.

It's possible to make a good parametric F-test in financial, legislative and security risk. A non-parametric test can be made in operational and personal risk and in a weak law enforcement in particular fields. The competitiveness risk doesn't fill the conditions for making parametric as well as non-parametric test. That's the reason why the analysis of variance cannot be made or the results are not trustworthy when executing the test.

Table 5: Parametric F-test of risks variance analysis (source: own data processing).

\begin{tabular}{|c|c|}
\hline Risks & $\begin{array}{c}\text { F- test } \\
{[\text { P-value }]}\end{array}$ \\
\hline Financial risk & 0.00145 \\
\hline Legislative risk & 0.08034 \\
\hline Security risk & 0.15215 \\
\hline
\end{tabular}

Table 6: Non-parametric Kruskal-Wallis test of risks variance analysis (source: own data processing).

\begin{tabular}{|c|c|}
\hline Risks & $\begin{array}{c}\text { Kruskal-Wallis } \\
\text { test } \\
{[\text { P-value }]}\end{array}$ \\
\hline Operational risk & 0.00001 \\
\hline Personal risk & 0.03556 \\
\hline Weak law enforcement & 0.04739 \\
\hline
\end{tabular}

Primary interpretation of the results of the risks analysis from Tables 5 and 6:

- There's a probability of 95 per cent that we accept the assumptions that the variance of average values of financial risk are different in specific fields of the study; 
- There's a probability of 95 per cent that we can assume that variance differences of average values of legislative and security risk in particular fields of the study is statistically not important and thus we accept the assumptions of average values identity;

- There's a probability of 95 per cent that among the variance of average values of personal risks, there are the greatest differences among the fields;

- There's a probability of 5 per cent that the variance of operational risk, as well as a weak law enforcement risk, within particular fields are statistically significant.

\section{Survey assessment and discussion}

The submitted study is based on the presumption that safety is multifactorial and multilevel phenomena with its content, structure and functions overreaching not only the limits of one scientific branch, but even all the scientific disciplines. Križovský [11] issues from the view of the existential threats and their risks of settlement unit development. Attention is paid to environment safety and its aspects. He generates specific environmental limits of spatial development as basic determinants of the development of cities and municipalities.

The view of the relations between procedural theories and the assessment processes in their content and time determination shows various positions of the assessment within master planning processes and their development. We examine the immediate saturation of human needs at the time of the assessment, but we assess the characteristics and the influence on a spatial system and its elements even in relation to future functional use. Generally, the presumption that the limits and restrictions do not operate in the area isolated, but synergistically, was confirmed. The determination of limiting and restricted factors for specific activity comes from the consideration of a functional relation between the characteristics of master planning elements of abiotic, biotic and socioeconomic complex and the objective activity of social practice. We consider the value characteristics, or possible interactions of the characteristics that are latent during the assessment. However, they can be activated by the execution of specific activity in the assessed territory in the future. We observed even the relation of the execution of particular activities of the settling to the qualities in a more detailed way by the examination of a spatial quality of the settlement systems. It's, more or less, an objective process, even though the determination of the value scale is of the subjective perception character. If the values of the parameters reach certain values, the system changes from a stable to a liability state. If this critical point (bifurcation point) is interfered with, the system structure is changed and achieves a new stable system. In this context, a synergy is the key phenomena in the evolution movement of complex systems (settlement systems).

We can conclude that there is an insufficient efficiency of economical instruments of environment management and their spatial implementation within the research. From the point of view of economic and environmental efficiency, 
we can consider the current approach as ineffective, because fulfilling the stimulation and the allocation function is the part of the environment goals. In this context, we agree with the statement of Floreková and Čuchranová [6] that the capacity limit of an environment set by polluters must be implicitly set by the amount of the payments that polluters pay. In order to affect the polluters of an environment in terms of economic theory, their optimal level should be derived from the amount of utmost expenses necessary to decrease the pollution unit.

\section{Conclusion}

Economic instruments of environment management are indirectly related to the absence of complex professional management. The insufficient integrity of these activities is closely related to the cohesion of risk management, territory marketing and a completely undervalued and abandoned prevention function of possible socioeconomic impact on further development. These activities don't possess an adequate instrument, neither of methodic nor legislative scope within the master planning, as their interconnection with the execution stage is the basis.

It's necessary to prepare suitable solutions to decrease unfavorable consequences resulting from any risk situations. An additive integrity of particular factors is not crucial in this process; what is crucial is their mutual cooperation in the final synergistic quality within the space-time with the emphasis on the moments of revolutionary changes in the settlement systems and their related complex perception of the safety of the objective territory as a compact unit.

We can conclude that our progress in master planning misses the strategic objectivism of economic and social goals and qualified foundation not only for applying the principles of sustainability and their classification into the process of documentation creation of the master planning. From the point of view of master planning, there is insufficient understanding of a complex activity of it, predominantly its function of coordination and all the aims closely related to the development of an urbanized and natural country in the Slovak Republic. The novelty of the submitted approach consists in modern view of the integrity as a persisting process of quantitative and qualitative progressive developmental changes in the context of sustainable spatial development.

\section{Acknowledgements}

The authors would like to thank to the Ministry of Education of the Slovak Republic for the support. Research was funded by KEGA Project no. 005DTI4/2014.

\section{References}

[1] Jelšovská, K., Mikulová, E. Environmental security, In.: University of Žilina, Faculty of special engineering, vol. 1, pp. 86-88, 2010. 
[2] Šimák, L. Crisis management in public administration, Faculty of special engineering, University of Žilina, p. 245, 2004.

[3] Janošíková, G., Hudecová, D. Risk assessment methodology selected at national level, Ministry of interior of the Slovak Republic, [online] http://www.minv.sk/?Dokumenty_na_stiahnutie_CO, p. 30, 2013.

[4] Holla, K. and kol. Complex model of risk assessment of industrial processes MOPORI. n: Communications: scientific letters of the University of Žilina, vol. 15, no. 2, s. 63-68, 2013.

[5] Kelíšek, A., Klučka, J., Ondrušek, M., Strelcová, S. Economic security A principal component of multilevel security concept in global economy, In: Communications: scientific letters of the University of Žilina, Vol. 13, No. 2, s. 44-48, 2011.

[6] Florekova, L', Cuchranova K. Applying of the economic tools in the system of environmental managing, In.: Acta Montanistica Slovaca, Faculty of Mining, Geology, Process Control and Geotechnology (FBERG), Kosice, Vol. 6, pp. 225-230, 2001.

[7] Finka, M., Interdisciplinary Aspects of Spatial Quality Development in Settlement Systems, Bratislava: Road, p. 165, 2001.

[8] Finka, M., Kluvankova-Oravska, T. The concept of polycentricity in current theory and practice of management area, In: Forecasting papers, Forecasting Institute SAV Bratislava vol. 2, no. 1, pp. 23-37, 2010.

[9] Havierniková, K. Selected aspects of clusters initiatives in the field of industry in the Slovak republic In: Metal 2012: 21st international conference on metallurgy and materials, Tanger, 2012.

[10] Statgraphics, Software Statgraphics Centurion XVII, 2014 [online] Available at: http://info.statgraphics.com/download-trial?\&_hssc $=\&$ $\mathrm{hstc}=251493209.2 \mathrm{c} 537766 \mathrm{ae} 0 \mathrm{c} 7 \mathrm{a} 3$ eada5bf7a11a4c695.1418632351830. $\overline{1}$ 418632351830.1418632351830.1\&hsCtaTracking=d8e0219d-8368-487da39b-8f69849e1868\%7Cca0011b4-305c-43fe-b137-ea927ae0ac37

[11] Križovský, S. Identifying risk the security of citizens, In.: Kosice security revue, vol. 3, no. 2, pp. 94-104, 2013. 